
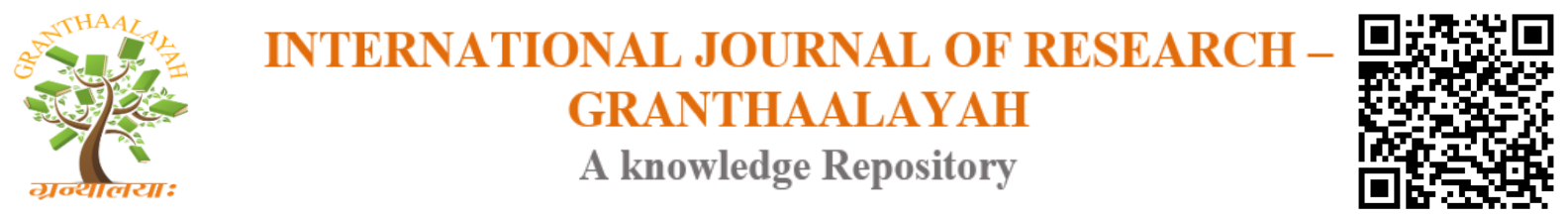

Management

\title{
BULL VS BEAR MARKET- AN INVESTMENT GAME ANALYSIS USING MOVING AVERAGE METHOD
}

\author{
Biswajit Rout ${ }^{* 1}$, Ayesha Mohanty ${ }^{2}$, Akash Kumar Kacharia ${ }^{3}$ \\ *1 Assistant Professor, Regional College of Management, Bhubaneswar, India \\ ${ }^{2,3}$ Regional College of Management, Bhubaneswar, India
}

\begin{abstract}
This paper aims to analyse and interpret the investor perception about investing in stock market. The market is often referred as to bull or bear market. This is key importance for financial decisions and economic analysis. The market behaves differently in these two phase. The bull market is identified when there is constant rise of stock prices whereas bear market is referred when there is fall in stock prices. These phases occur due to different trends of market or economy. Investor sentiments get affected by this. The paper tries to identify and provides understanding about the factors that causes and how it affects the psychology of investors.

There are different analysis techniques used by analysts. The popular and common analysis theories are Fundamental Analysis and Technical Analysis. This paper is based on technical analysis of different category of stock with respect to wide spread industry like FMCG sector, Banking sector, Oil and Natural Gas sector, Automobiles sector and Pharmaceutical Sector etc. The paper also tries to establish whether the market is having a Bull Run or bear. The movement of stock prices is analysed in technical analysis. The data of stock prices are collected from NSE official site. The analysis in done for 5 years span starting from April 2012 to Mar 2017. Even to understand better, analysis of the stock is done on 100days moving average. Prevailing news during those times are also considered to interpret the behaviour of the investors.
\end{abstract}

Keywords: Bull Market; Technical Analysis; Moving Average; NSE; Investor.

Cite This Article: Biswajit Rout, Ayesha Mohanty, and Akash Kumar Kacharia. (2017). "BULL VS BEAR MARKET- AN INVESTMENT GAME ANALYSIS USING MOVING AVERAGE METHOD." International Journal of Research - Granthaalayah, 5(11), 425-443. https:// doi.org/10.29121/granthaalayah.v5.i11.2017.2376.

\section{Introduction}

Investment: Investment is the employment of funds on assets with an aim of earning income or capital appreciation. It has two attributes: Time \& Risk. Present consumption is sacrificed to get a return in future. With the availability of variety of investment alternatives such as negotiable or non-negotiable financial instruments, it gives rise to the questions like where to invest and when to invest? And one of the preferred investments, made by the investors is "Stock". The stock is a 
mere collection of shares of a member of a company in a lump sum. When the shares of a member are converted into one fund is known as stock. As it is a negotiable or transferable financial instrument, it enables stock trading which means selling and buying of shares basing upon the fluctuating market conditions. Stock trading is referred as an investment game in bull and bear market because each trading day is analogous to a struggle between optimists \& pessimists who buy and sell at various prices given different expectations.

A Bull Market erupts when optimists dominate and prices tend upwards along with excess of demand \& inadequate supply. The investor's positive inclination towards market encourages more investment and rise in stock prices.

While a Bear Market shows the downward movement of the market, which indicates investors' reducing interest guided by much other factors.Stock market is a dynamic market which involves frequent rise and fall in stock prices with effect to various political, economic and climatic factors, which eventually gives rise to an investment game among the investing public.

\subsection{Technical Analysis}

It is a process of identifying trend reversals at an earlier stage to formulate the buying and selling strategy. With the several indicators, they analyse the relationship between the price-volume and supply-demand for the overall market and the individual stock.

\section{What is a Trend?}

A trend is the direction of movement. The share prices can either increase or fall or remain flat. The three directions of the share price movements are called as rising, falling and flat trends. Every rise or fall in share price experiences a counter move. If a share price is increasing, the counter move will be a fall in price or vice-versa. The share prices always move in a zigzag manner.

\subsection{Trend Analysis}

A trend analysis is a method of analysis that allows traders to predict what will happen with an individual stock or the market in the future. Trend analysis is based on historical price movements. Technical analysts mainly focus on the past history of prices and study two basic market data-price and volume. They mainly predict the short-term price movements rather than long term.

While, fundamental analysts study the financial strength of corporate, growth of sales, earnings $\&$ profitability along with industry and economic conditions. They try to find out the long term value of shares.

Trend analysis supports to predict a trend such as bear market run, until the data suggests a trend reversal, such as a bear-to-bull market.

Moving Average Chart: Moving average is the average price of a stock at a given time.A Simple Moving Average (SMA) is calculated by adding the stock's price for the most recent "n" 
time periods and then dividing it by "n". If we have to calculate a 100 days SMA price of a security then we have to add the prices for the last 100 days and divide it by 100 .

\section{Objectives}

- The main objective of this project is to understand the investor perception about the stock market.

- To study the market trend of the various actively trading stocks in the NSE and BSE.

- To study the various macro and micro economic factors of the business environment that affects the market indices.

- To observe the bearish and bullish markets with the help of charts.

- To fetch a complete understanding of the changing market conditions, this can be extremely beneficial for sensible investment.

\section{Limitations}

- The whole project is totally based on historical data.

- The project will act as a basis for estimation and prediction but sometime it can give absurd results as we all know that the future is uncertain.

- Here only indices like NIFTY 50, NIFTY 100, BSE Sensex and BSE 100 are taken into consideration. But there are many more indices related to Indian stock market.

- Only a few stocks are taken into consideration on the basis of sampling which may or may not be sufficient to get the desired conclusion

\section{Literature Review}

Brown \& Jennings (1989) in the article on "Outperformance of Technical analysis" showed that technical analysis has value in a model in which prices are not fully revealing and traders have rational speculation about the relation between prices and signals.

Brook, Lakonishok\&Lebaron(1992) in their study titled"Simple Technical Trading Rules \& Stochastic Properties of Stock Returns", examined 26 technical trading rules using 90 years of daily stock prices from the Dow Jones Industrial Average up to 1987 found that they all outperformed the market.

Malay. K. Roy \& Madhusudan Karmakar "Stock Market Volatility Roots \& Results"(1995) is based on measurement of stock market volatility for the period 1935- 1992 i.e. 58 years to compare the current level volatility with these average measures to understand whether it is above or below the historical level.

Lui\& Mole (1998) report the outcomes of a questionnaire survey conducted in Feb 1995 on the use by foreign exchange dealers in Hong Kong of fundamental and technical analysis. They found that $85 \%$ of respondents rely on both methods and again Technical analysis was popular at shorter time horizons. 
Lo, Mamaysky and Wang (2000) examines the effectiveness of technical analysis on US stocks from 1962 to 1996 and finds that over the 31-year sample period, several technical indicators do provide incremental information and may have some practical value.

Macdonald (2001) studied the inter-relationship among Central \& Eastern Europe (CE) stock market indices as a group and three developed markets (US, UK \& Germany) and found significant long-run co-movements among them.

Cesari and Cremonini (2003) have made an extensive simulation comparison of popular dynamic strategies of asset allocation and find that technical analysis only performs well in Pacific markets.

Chowdhury \& Rahman (2004) in the "Empirical relation between Macroeconomic Volatility \& stock market volatility of Bangladesh" found that predicted volatility of macroeconomic variables is related with that of stock return in Bangladesh capital market with causality running from Macroeconomic Volatility toward stock market volatility.

Chowdhury, Mollik\& Akhter (2006) in their paper "Macroeconomic Volatility influence Stock Market Volatility" found that industrial Granger-causes stock market volatility and stock market volatility Granger causes inflation uncertainty. Non-existence of the relationship between stock market \& exchange rate fluctuation can be explained by the Fixed Exchange Rate Regime.

Coel.H.Park \& Scott.H.Irwin (2007) on "The Profitability of Technical Analysis" to review the evidence on the profitability of technical analysis. The empirical literature is categorised into 2 groups- early and modern studies where Technical trading strategies are profitable in foreign exchange markets \& modern studies indicate that Technical Trading Strategies generate economic profits in variety of speculative markets until the early 1990s.

Joshi \& Pandey (2007) examined the nature of the volatility in the Indian Stock Markets using closing prices of S\&P CNX Nifty \& BSE Sensex stock prices and concluded that both the stock markets exhibited the volatility clustering and volatility persistence.

S. D.Vashishtha, Umed Singh \& Rajesh Kumar(2013) in the paper "Prediction of Buy \& Sell Signals using Moving Average Tool of Technical Analysis" found that Moving Average Tool is an effective tool for predicting buying \& selling signals, but other factors must also be considered.

Hemal Pandya(2013) in the article on Technical Analysis for Selected Companies of IT sector (HCL, Infosys, MPHASIS, WIPRO \& TCS)used the following techniques- Line Chart, Column Chart, Candlestick chart, Exponential Moving Average(EMA), Moving Average Convergence Divergence(MACD), RSI \& ROC and forecasted a large growth of IT companies in future.

Nithya\& G. Thamizehelvan (2014) in "Effectiveness of Technical Analysis in Banking Sector of Equity Market" used technical tools- Candlestick Charts, RSI, MACD found it can be used to predict the possible future swings of stock prices but if it is used improperly, it can give false signals. 
Aparna Bhatia \&Binny (2014) conducted a research on "Analysis of stock market volatility: A comparative study of India \& China" and highlighted that there have been multiple reasons, local $\&$ domestic, leading to volatility in the both Indian and Chinese stock markets. The prominent ones being political reasons, economic policies, regulations of the Govt., the net effect of FIIs, civil disturbances in the country etc are quickly transmitted to the markets.

Gang LI \&Jin Zhu (2014), in the paper on "Effectiveness of Technical Indicators with the Volume" have chosen the Volume Weighted Moving Average (VWMA) \& SMA based on 2139 stocks from 1 Jan 2003- 1 Jan 2013 in China's A share market., and concluded that technical indicators which take into account the volume information is more effective than pure price index in stock market.

\section{Analysis of Nifty50 Using Line Chart Techniques}

For the analysis of the NIFTY50 through line chart, the closing points are required. The data of past 5 financial years' closing points are taken from NSE official site. The time frame of 5 years is taken so that the report can cover the market conditions with reasons of rise and fall in Nifty. Each year is divided into 12 months of trading data for taking adjusted closing points for each month. Each year is plotted differently in 5 different line charts so it would help to see the prominent rise and fall in Nifty points during that year.

\subsection{Line chart for 1 st Apr $2012-31^{\text {st }}$ Mar 2013}

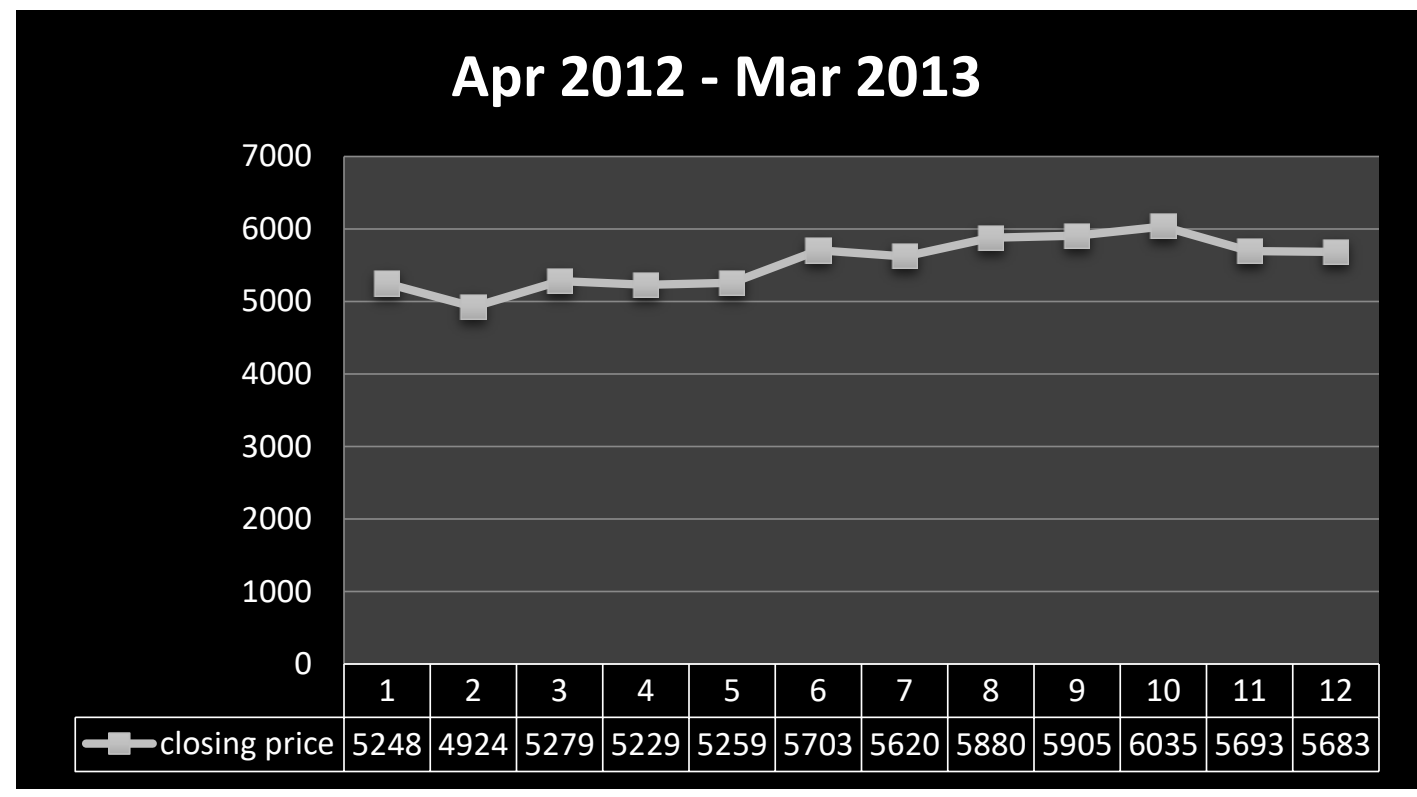

\section{Interpretation}

As financial year $1^{\text {st }}$ Apr $2012-31^{\text {st }}$ Mar 2013 is considered for the analysis, the above line chart is plotted as per the historical data collected from the official website of NSE. According to the graph, the year started with a closing price of Rs.5248.15 and gradually falls with a decrease of 324(approx.) points, touching an closing price index of 4924.25 at the end of May 2012. Further, 
it moves slightly upwards hitting an index figure of Rs.5278.9 and maintained a similar trend for consecutive two months with 5229 and 5258 indicating negligible fluctuations in market conditions. Then the market follows a upward trend, touching new peaks of 5703.3 in Sep 2012 and 6034.75 in Jan 2013 signifying favourable market conditions. In between these 5 months, the market index had gone through a trough of 5619.7. After Jan 2013, the market gradually decreased with a closing price of Rs. 5682.55 at the end of the year.

\section{Reasons behind the fluctuations in the Nifty50 during the FY2012-13:}

- According to the economic survey for 2012-13, Indian stock market gave the second highest returns globally, driven largely by higher inflows from foreign institutional investors (FIIs).

- Further during the FY (Apr- Dec 2012), the rise in the indices stood at $11.51 \%$ in the case of the nifty.

- In 2012, FIIs bought equities worth $\$ 24.4$ billion in 2012, about 5 billion below record purchases 2 years ago.

- The economic and political developments in the Euro zone area and the US had their impacts on markets including India.

- The resolution in the "fiscal cliff" in the US had a positive impact on the market worldwide including India. At the end of Dec 2012, 1759 FIIs were registered with market regulator SEBI.

- But again there is a slight downward trend observed toward the end of the year, mainly due to the decrease in the rates of savings of household sector in physical assets from $15.8 \%$ to $14.8 \%$. In addition to that, spending cuts enforced by finance minister P.Chidambaram to $5.3 \%$ against $6.8 \%$, projected earlier, to pare the fiscal deficit during 2012-13. Estimated decrement in Gross Domestic Savings (GDS), constituting 30.1\% of GDP at market prices, against $31.3 \%$ in the previous year.

\subsection{Line chart for 1st Apr $2013-31^{\text {st }}$ Mar 2014}

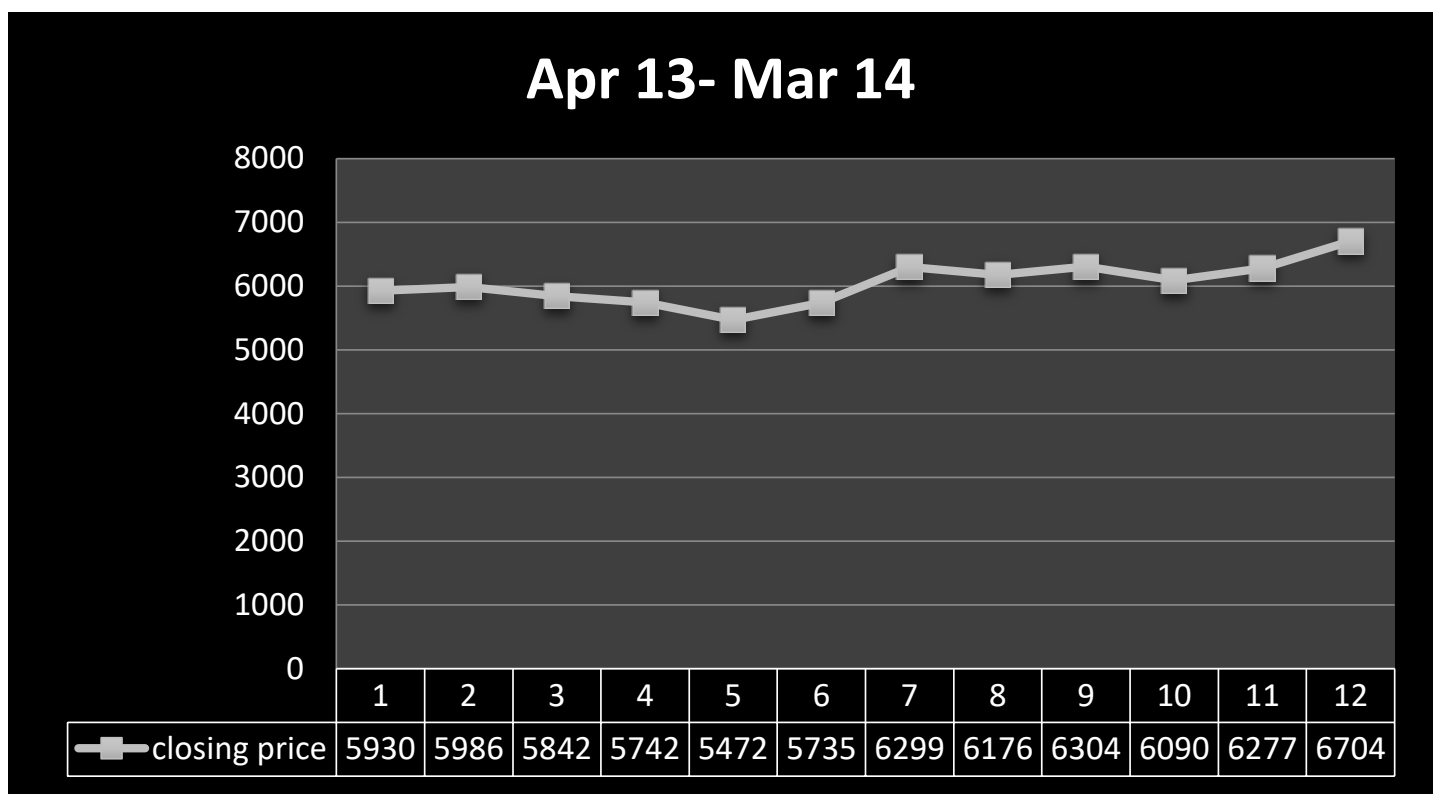




\section{Interpretation}

The year started with price level of 5930.2 points and maintained it up to the month of May 2013. Then, it again fell to 5842.2 points in the month of Juneand gradually decreased by 100 300 points and finally reached at trough point of the year i.e. 5471.8 in the month of Aug. After Aug, it progressed with increase in points and arrived at peak i.e. 6299.15and faced a slight fall of 220 points (approx...) touching 6176.1. Further, it regained its position in the month of Dec. at 6304 points following a decrease of 210 points in the market indices approximately, closing at 6089.5 in the month of Jan 2014. Gradually, moving upwards and ending at a new high of 6704.2 in the month of Mar 2014.

\section{Reasons behind the fluctuations in the Nifty50 during the FY2013-14:}

- The ultimate picture measures as an improvement over the year gone by. And the uptick in growth would be driven by a gradual revival in industrial production and services sector growth.

- The easing of core inflation due to lower/stable domestic and global demand conditions to put some downward pressure. Overall inflation is expected to moderate in FY14, although countervailing forces from an increase in minimum support price shall restrict the decline which had a slight impact in the $1^{\text {st }}$ half of the year.

- RBI said growth in the second half of 2013-14 might turn out to be marginally higher than in the first half, mainly due to a rebound in farm output and better exports.

\subsection{Line Chart for April 2014 - March 2015}

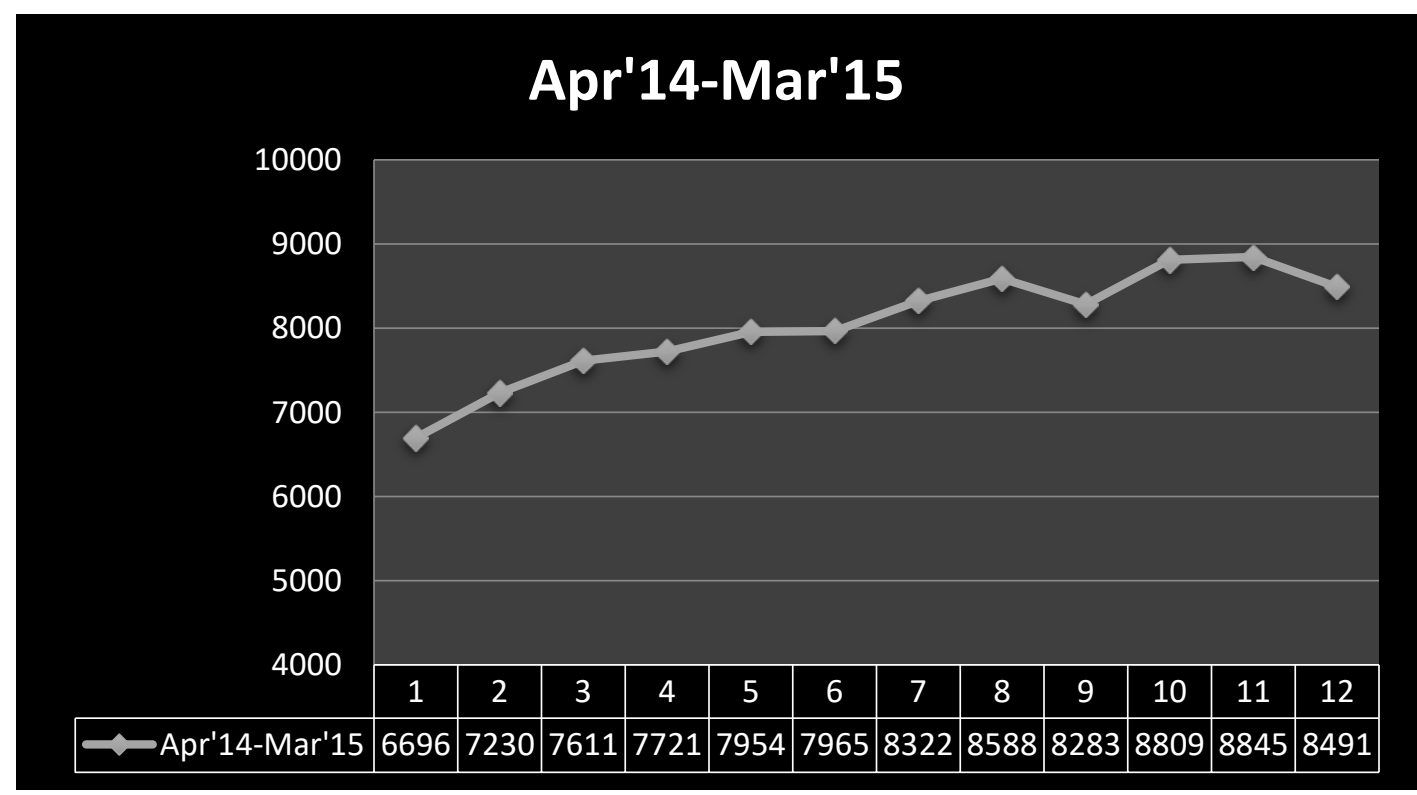

\section{Interpretation}

The year started with a value of 6696.4 points and gained 533 points in the subsequent month. And again there was a steep rise of around 400 points, reaching at 7611.4.In the following two 
months of July and Aug, the market index showed a significant rise of 100 to 400 points, consecutively in the month of Aug, Sep \& Oct. Again it showed a rise of 200 points in Nov. Then, in the month of Dec, there is a fall of around 300 points, but it regained its with a new high of 8808.9. Further it maintained its level in the next month of Jan 2015 and following with a steep fall of around 350 points.

\section{Reasons behind the fluctuations in the Nifty50 during the FY2014-15:}

- Narendra Modi became India's new prime minister with a clear mandate to govern Asia's third-largest economy. The BJP and its allies stormed to power by winning 336 of the 543 seats in the Lok Sabha, riding on Modi's promises to create more jobs and push India back on the high growth path.

- During the start of the month July the benchmark index was touching new high. The expectation of 1st Union Budget by the new government also drove the market high. After the budget announcement the market did not appreciated as much it was expected. But it saw many reforms which solidified investor confidence. The PM's speech about bright future further boosted the market. FIIs inflow increased mainly from Russia. Inflation for the July-August was low which supported the Bull Run.

- In October the benchmark indices rose further crossing 8500 points and lingered just below 9000 points. Traders believed the stellar return from the corporate was the reason further boost in the market. Stocks of oil and gas, consumer durables, capital goods, healthcare, fast-moving consumer goods (FMCG), public sector units, realty, metal and banking rallied the benchmark.

- In mid-December the index went to its 12 year drop. The reason for this was weakening of rupee in 13 month lowest. Concerns over growth were prevailing as crude oil prices crashed to fresh multi-years low, accelerated selling activity was also the reason of the fall.

- In January-February 2015, the bullish run completed its full year. The surprise interest cut by RBI Governor RaguramRajan to boost the economy was appreciated by the stock market. Domestic investment cycle and buying of shares by foreign investors were the reasons driving markets

- In March 2015, during the start of the month the fear of US hike of interest rate slumped the market. The unemployment rate in US as decreased this speculated the traders that the interest rate may get increased which have a negative impact on emerging market like India. Later the month saw that government was not able to pass some key reform bills like Goods and Sales Tax Bill and Land Acquisition Bill which further affected the investor sentiments. The crude oil prices surged, the concerns that the proxy war between Arab nations and Iran may lead to higher crude prices in future also tumbled the investors. 


\subsection{Line Chart for April 2015- April 2016}

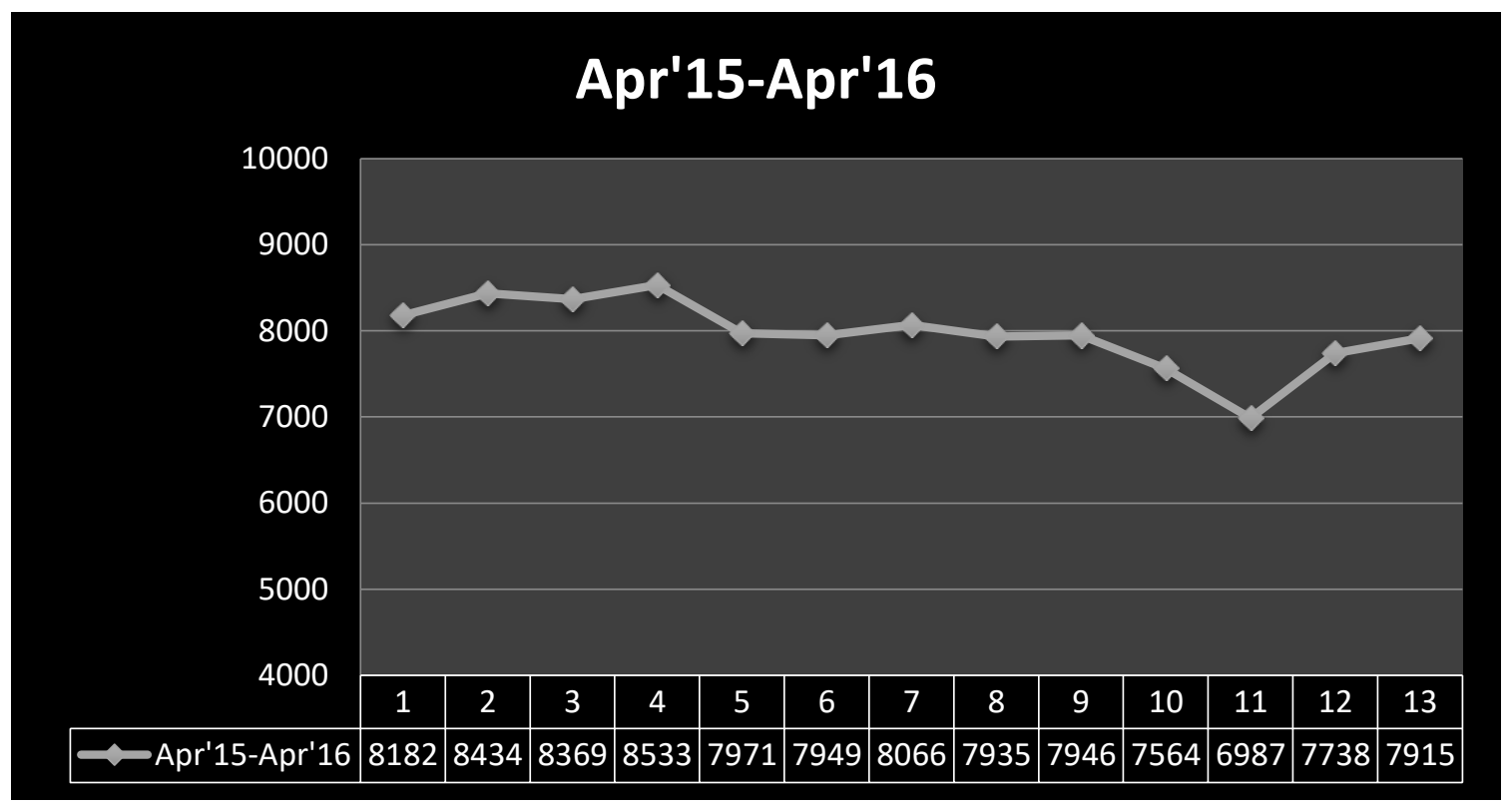

\section{Interpretation}

The year started with a market index of 8182 and gained approximately, 250 points, touching a high of 8434. Then, there is a little fall in the value, closing at 8369 in the month of June. Surprisingly, there is a steep rise of around 200- 400 points, shown in the month of July, Aug \& Sep. And in the month of Oct 2015, the market index reached at its peak of the year i.e. 8066. And further there is an approximate fall of 100 points in the month of Nov, which continued to the next month. Then, there is a sudden decrease of around 400points, reaching at 7564. In the month of Feb 2016, the market index touched the trough of the year, i.e. 6987, and again closed the year at 7738 .

\section{Reasons behind the fluctuations in the Nifty50 during the FY2015-16:}

- In April 2015, the NSE benchmark index slipped further after the March. The main reason of it was FII were selling of shares due to retrospective taxation as announced by government. The investor confidence further got affected when rupee weakened. Healthcare sector suffered the most. Analyst were not concerned and felt the bull run will continue and pointed out this was the right time to get good stock for cheap to improve their portfolio.

- In May-June 2015, the index was lingering below 8500 points. During the month May the index could not regain its past run due to weakening of rupee. The results of some blue chip companies were not up to the expectation. The main reason was traders concern over the opposition and government for passing of GST Bill.

- In June, the index fell further. Below normal monsoon prediction as the investor concern were over the output for future. RBI's conservative stance on rate outlook was another reason for the index to not perform well. The performance of major sectors was not satisfactory which lead to fall in index. 
- In July 2015, the fear of monsoon effect was decreasing in investor sentiments. The stability of rupee and lowering of oil prices brought hopes for the investors. The expectation of GST bill to be passed also brought in some optimism with the investors. This resulted in rallying back 8500 points in this month.

- Global markets and China stocks crashing caused pessimism among investors.

- In April 2016, after two month low the benchmark index gain stability and increased. The favourable monsoon prediction helped to restore investor confidence.

\subsection{Line Chart for Apr 16- Mar 17}

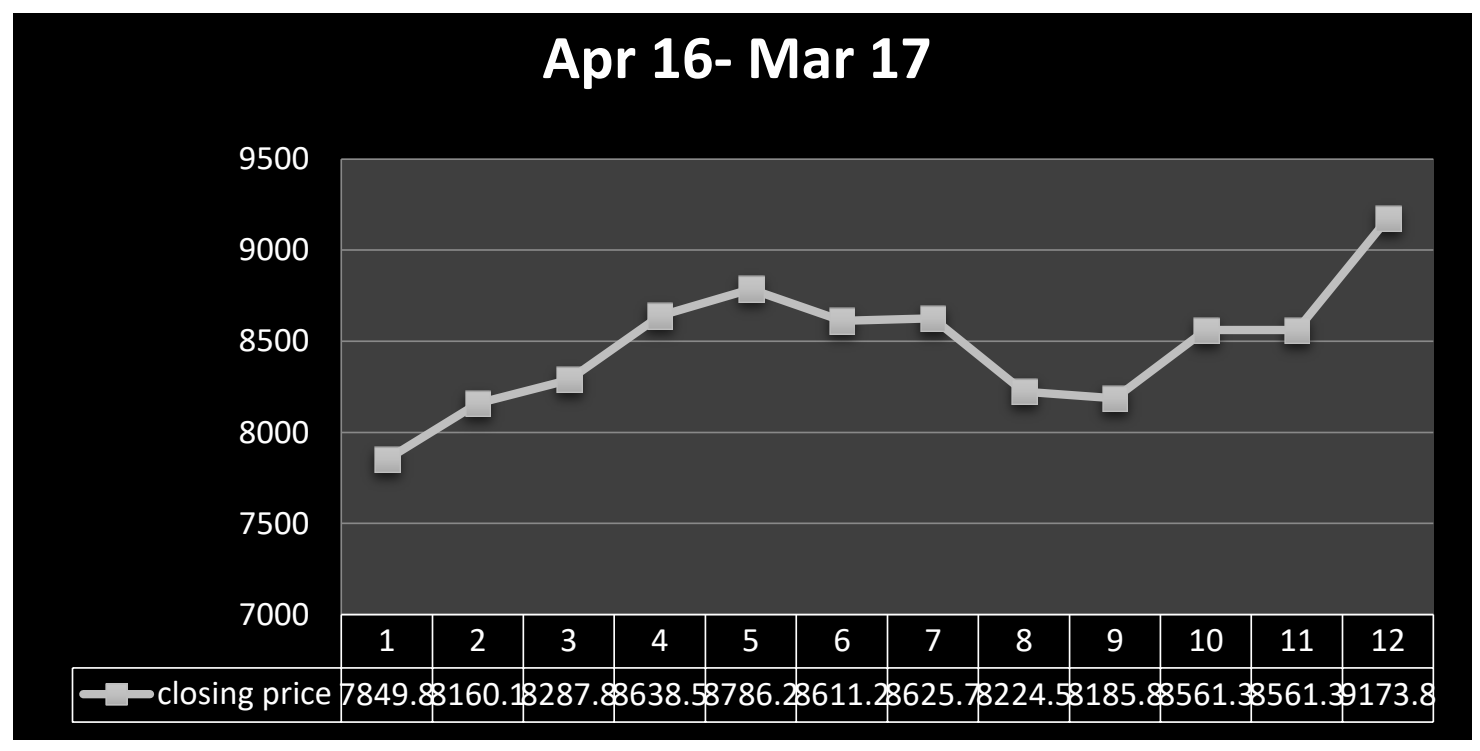

\section{Interpretation}

From the above chart, it can be concluded that, in the FY 2016-17, the NSE index started with a price value of Rs.7849.8 and gained 311 points reaching at a point of 8160.1 in the month of May 2016. Further it maintained the upward trend up to the month Aug 2016, reaching at new high of 8786.2 points. Then gradually lose approx... 200 points till the month of Oct 2016 . In the month of November, NSE index got miserably hit by the Govt's announcement of Demonetisation Policy, which reduced the liquidity in the market, losing 400-500 points in the index resulting into a trough point of 8185 points. But again with the recovery in the market condition, the index price began to rise by gaining 400 points and ultimately touching a new peak of 9173 points. Along with that, prediction of normal monsoon by the IMD had appositive impact on the market indices

\section{Reasons behind the fluctuations in the Nifty50 during the FY2016-17:}

- The Ministry of Finance declared that all tax payers who are not under any tax slabs are bound to give information about their undisclosed income on or before $30^{\text {th }} \mathrm{Sep}$, otherwise heavy penalties would be imposed on them, if found guilty.

- Brexit Vote(June 2016): Britain voted to exit the EU winning with $51.9 \%$ votes in a historic referendum, followed by the resignation of Prime Minister David Cameron. 
- Surgical Strike on Pakistan(Sept 2016): The surprising declaration of Director General of Military Operations about the surgical strike carried out by Indian Army on terror launch pads in Pakistan, in the press conference, generated fear among the investors.

- Demonetisation (Nov 8): Removing approximately $86 \%$ of the currencynotes from the economy, overnight, was the boldest decision taken by the NDA govt. to alleviate black money circulation and terror funding, gave a major hit the Indian Stock Market.

- Republican Donald Trump elected as US President beating Democrat Hillary Clinton, consequently hitting the rupee value had a major blow to the economy.

- Inflows from FIIs and prediction of normal monsoon acted in favour of the market

\section{Sector Wise Analysis}

Here, 5 crucial sectors are chosen, which play a vital role in the Indian Economy, viz. Banking, Oil and Natural Gas, Pharmaceuticals, FMCG (Fast Moving Consumer Durables) \& Automobiles. The data is collected for the past one financial year i.e. Apr $16-$ Mar 17 and plotted in the line chart technique depicting closing price as well as 100 days moving average line. There is a thorough comparison between the two, so that a vivid understanding can be created by going through it.

\section{Banking Sector}

\section{- State Bank of India (Apr 16- Mar17)}

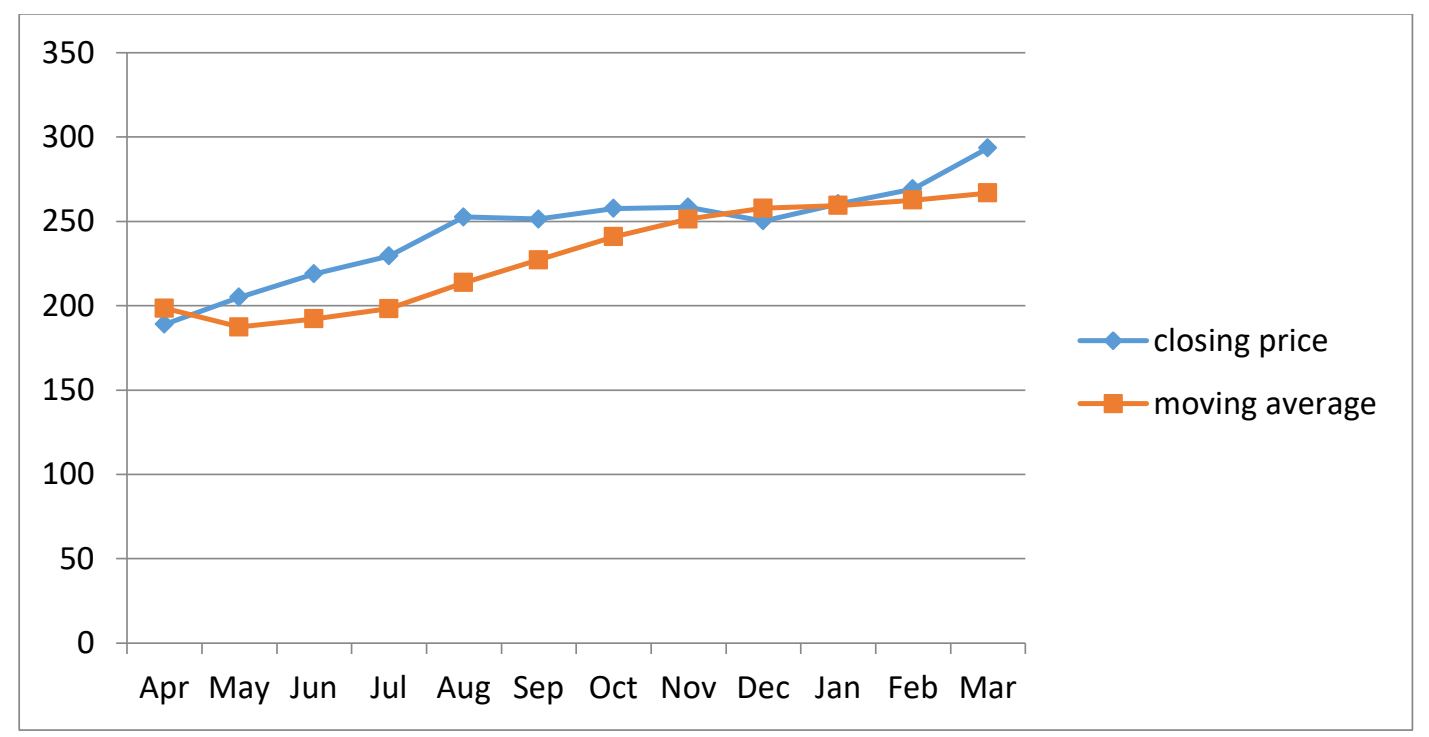

\section{Interpretation}

From the above chart, we could see that at the beginning of the year i.e Apr 2016, the closing price point is 189 while the simple moving average point is 198.41 showing a lesser gap between the two. Further, from May 2016 to Oct 2017, the closing price line is forwarding above the SMA line, which shows a buying opportunity for the investors but still the declining trend of the moving average is not favourable for the willing investors because the maintenance of the similar 
trend can be against the interest of the investors and the stock price may fall, entering into a bear phase.

Moreover, the current discrepancies in the banking sector such as a huge burden of bad loans on the Central Bank and the increment in the NPAs can be detrimental to it. Though the moving average line and the closing price line are moving closely to each other from Nov 2016 to Jan 2017, again there is a upward trend in the stock prices ending at Rs. 293.4.From the above analysis, we can conclude that the two trend lines are moving relatively closer to each other without any unexpected fluctuations with effect to the on-going crisis in the banking sector, attracting less investment.

\section{- HDFC Bank (Apr16 - Mar17)}

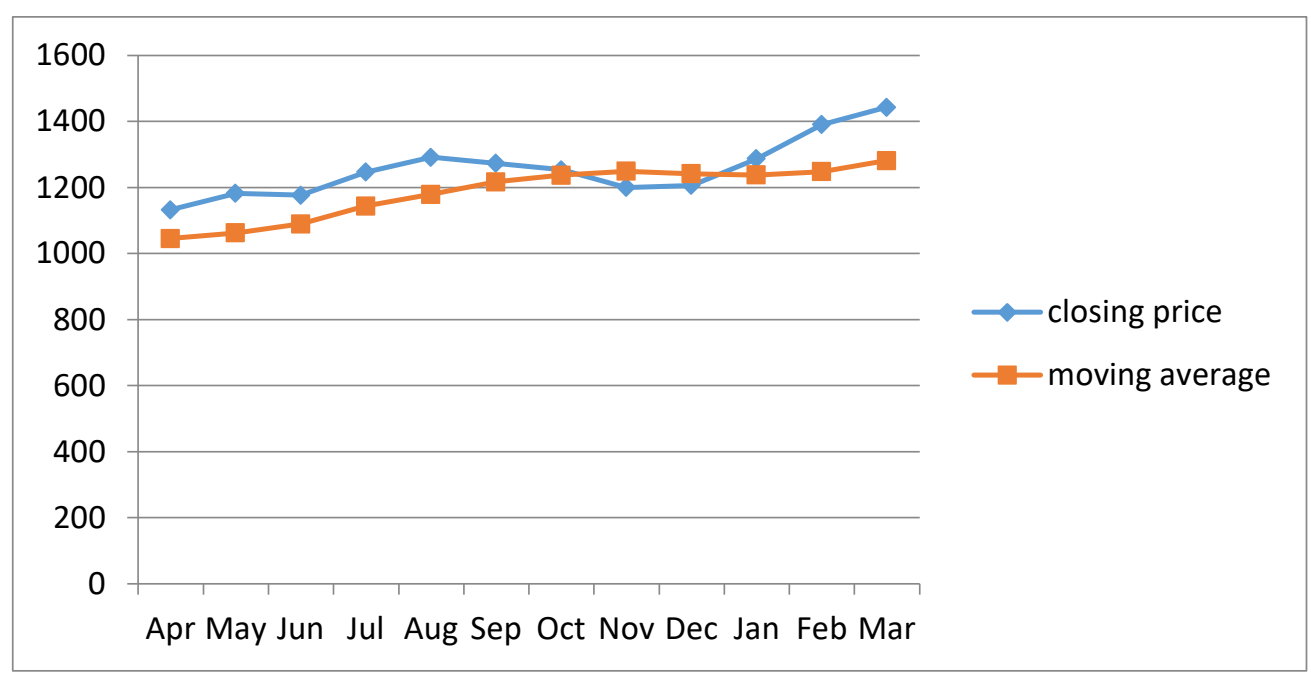

\section{Interpretation}

In the banking sector, one of the major private sector banks is HDFC Bank (Housing Development \& Finance Corporation) with a market capitalisation of Rs. 3, 92,954 crore, as per the report published by Business Standard. The year started with a stock price of Rs. 1132.35 and moved upwards with a gradual increase in the price level, with a margin of 60 and 30 (approx.) up to Jun 2016. In comparison to that, the SMA line is advancing below the closing price line indicating a buy signal. From July to Sep, there is a rise in the stock prices and in 0ct 2016, the moving average line crossed the price line and moved relatively closer to each other signifying a buying opportunity for the investors. From Jan 17 to mar 17 the stock prices went through a drastic change showing maximum rise and SMA line is slowly moving upward entering onto a good phase of the market. in Q4 FY 2016-17.

According to the report by Business standard,

- Best in class liability franchise

- Expansion of rural or semi-urban branches

- Improvement in productivity to digital focus are the major reasons behind the rise in stock prices. 


\section{Oil \& Natural Gas Sector}

\section{- ONGC (Apr 16- Mar 17)}

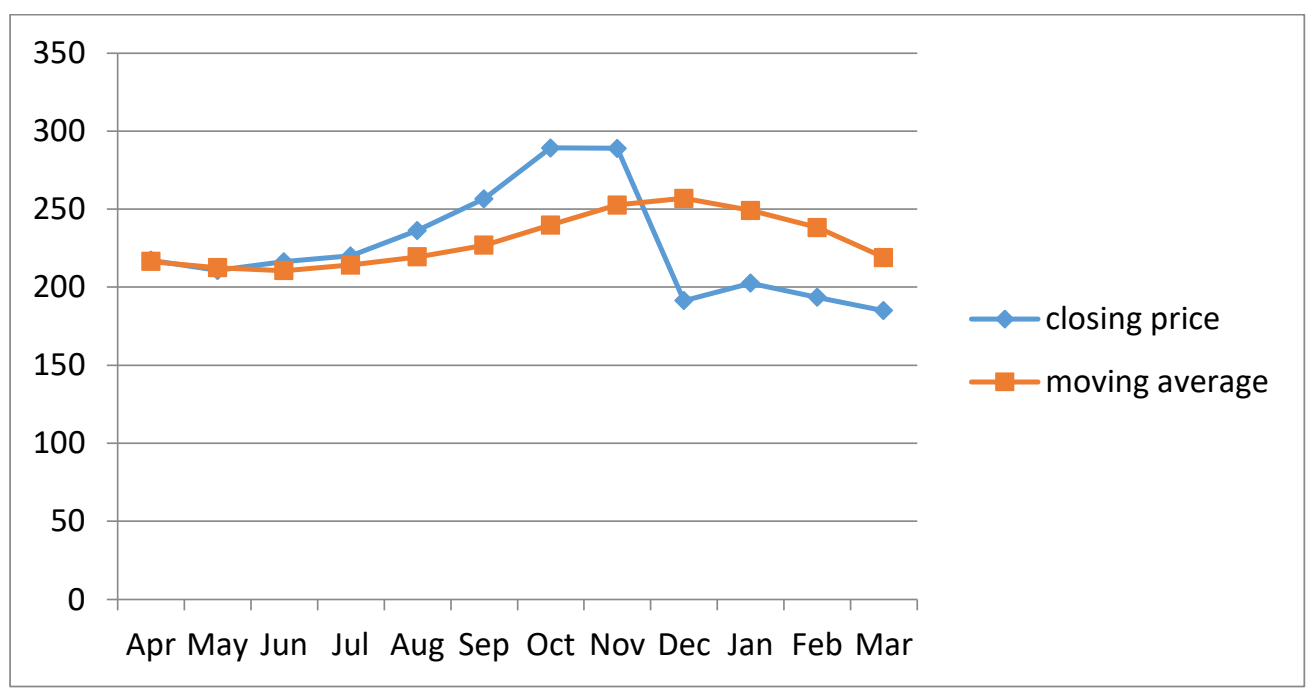

\section{Interpretation}

ONGC (Oil \& Natural Gas Corporation) had gone through a major hike in prices in the FY2016-17. At the beginning of the year, the stock price was at 217.25 and maintained it up to the month of July. Further, there was a gain of $20-70$ points, closing at 288.9 in the month of Nov. But with the major blow to the Indian economy and global politics by the "Surgical strike on Black Money' and "Arrival of Trump" respectively, made it to fall touching the low of the year 191.35 in the month of Dec. Here the downward penetration of the rising average indicates a further low and sell signal. Again there is slight rise in the stock prices, ultimately ending at 185 and creating a bear for the stock.

\section{- IOC (Apr 16 - Mar-17)}

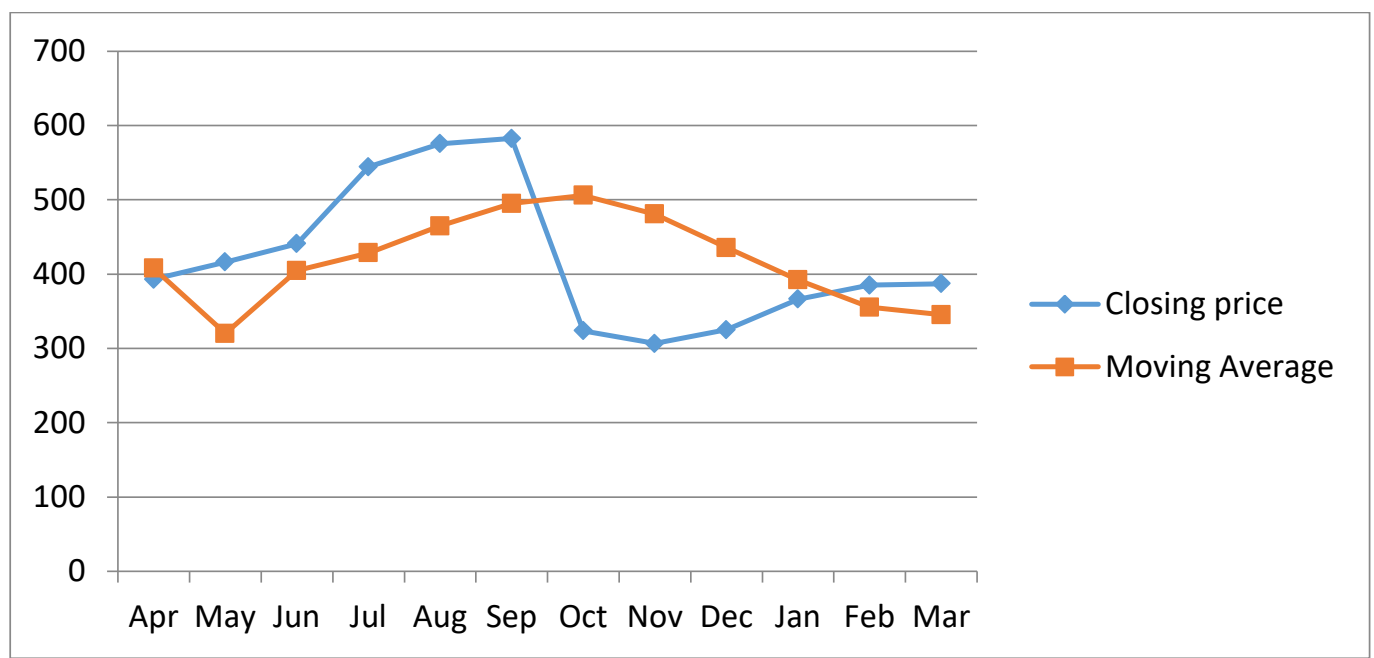




\section{Interpretation}

IOC (Indian Oil Corporation), another major contributor in the oil and natural gas sector of the Indian Economy, had also gone through a similar phase in the FY 2016-17. With a closing price of Rs. 393.05 in the month of Apr 2016, the stock prices gradually increased up to a high of Rs. 582.5 but faced abrupt fall in the month of Oct and again headed towards the price level of 400(approx..). As far as SMA line is considered, the moving average line was below the price line in the initial months of the year and dampened in the successive months following a downward trend in the prices of the stock. Still the IOCL ended the year on a triumphant note, because of the introduction of the huge welfare programme i,e Pradhan MantriUjjwalYojana. In addition to that, the inauguration of Paradip Refinery also helped it to excel in the market

\section{Pharmaceuticals Sector}

\section{- CIPLA (Apr 16 - Mar-17)}

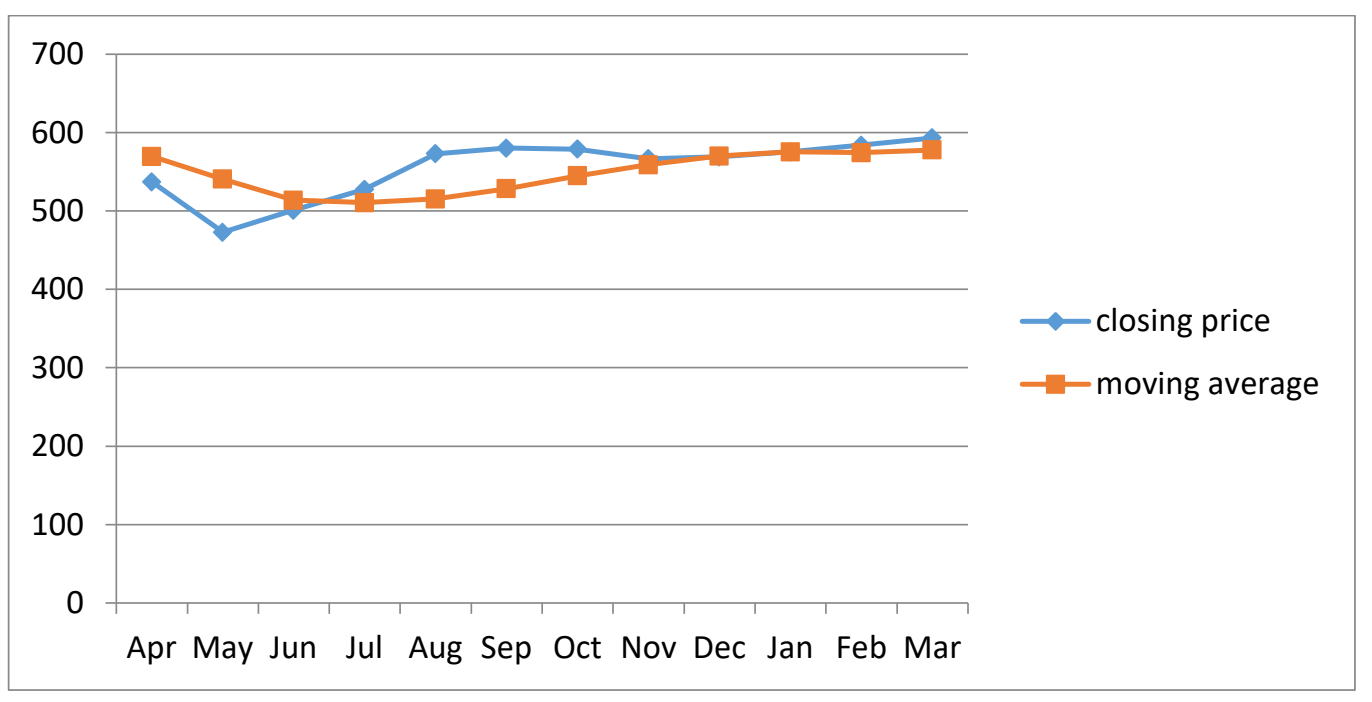

\section{Interpretation}

Generic drugs form the largest segment of the Indian pharmaceutical sector, with a market share of $70 \%$ (in terms of revenue). India is the largest provider of generic drugs globally accounting for $20 \%$ of global exports in terms of volume.

The above graph has been plotted showing the price fluctuations of the Cipla stock from $1^{\text {st }}$ Apr 2016 to $31^{\text {st }}$ Mar 2017. The open price of the stock was 537.10 in the month of Apr and the price on the last day was592.5. It was at its trough point on May, 2016 and peak point on $6^{\mathrm{t}}$ February. At the initial stage continued to stay between $450-500$ points till the end of June after which it again reached 500 mark and continued trading around and above it. In the middle of August and September it crossed 550 mark and 600 mark respectively but fell below 600 at the beginning of October and started to fall steeply in the month of November. It also stayed strong during demonetisation phase by rising almost every day up to December. It maintained its position between 550-600 in the intial days of February and moved across 600 points there. It 
maintained its state around 600 till $20^{\text {th }}$ April after which it fell to 550 and ended the period at 565. With reference to the SMA line, it was moving closer to its price line, showing a favourable phase for the stock price in the market. It may be due to the growing market size of Cipla, with the acquisition of 2 US-based companies, InvaGen and Exelan pharmaceuticals for US\$550 Million.

\section{- Sun Pharma (Apr 16 - Mar-17)}

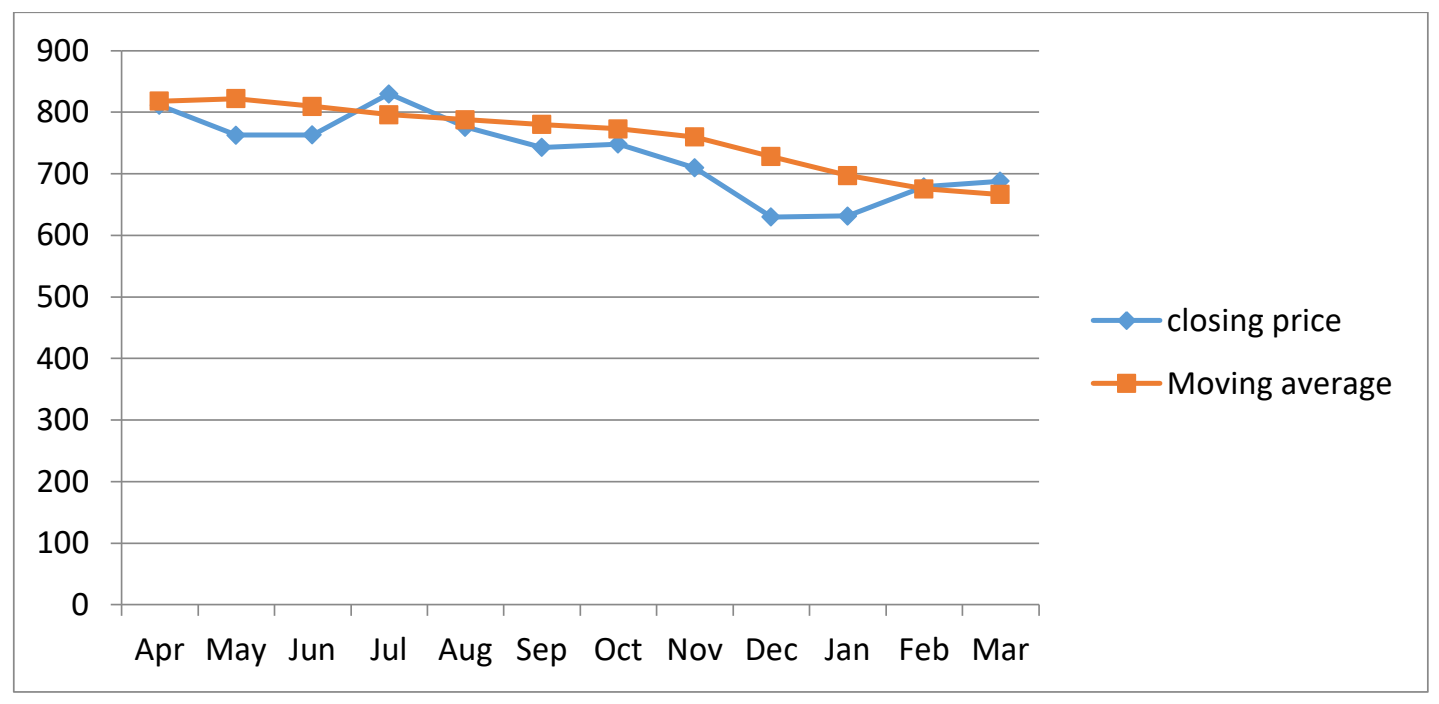

\section{Interpretation}

The above graph has been plotted showing the price fluctuations of the Sun Pharma stock from $1^{\text {st }}$ Apr 2016 to $31^{\text {st }}$ Mar 2017, data collected from nseindia.com. The open price of the stock was 815.10 in the month of Apr and the price on the last price was 688.15. It was at its trough point in the month of Dec 2016 and peak point on July 2016.

At the initial stage continued to stay between 800 to 700 points till the end of June after which it again reached 800 marks and continued trading around and above it. Then from Aug 2016 it diminished gradually touching a low of 630 points. . Then, it had gone through a slight increase in the points, ending at 688.15.In the month of Aug, the SMA Line coincided with the price line and moved downward, ushering into a bearish market. From the above analysis, it is clear that, the Sun Pharma stocks are heading towards a bear market 


\section{FMCG Sector}

- ITC (Apr 16 - Mar-17)

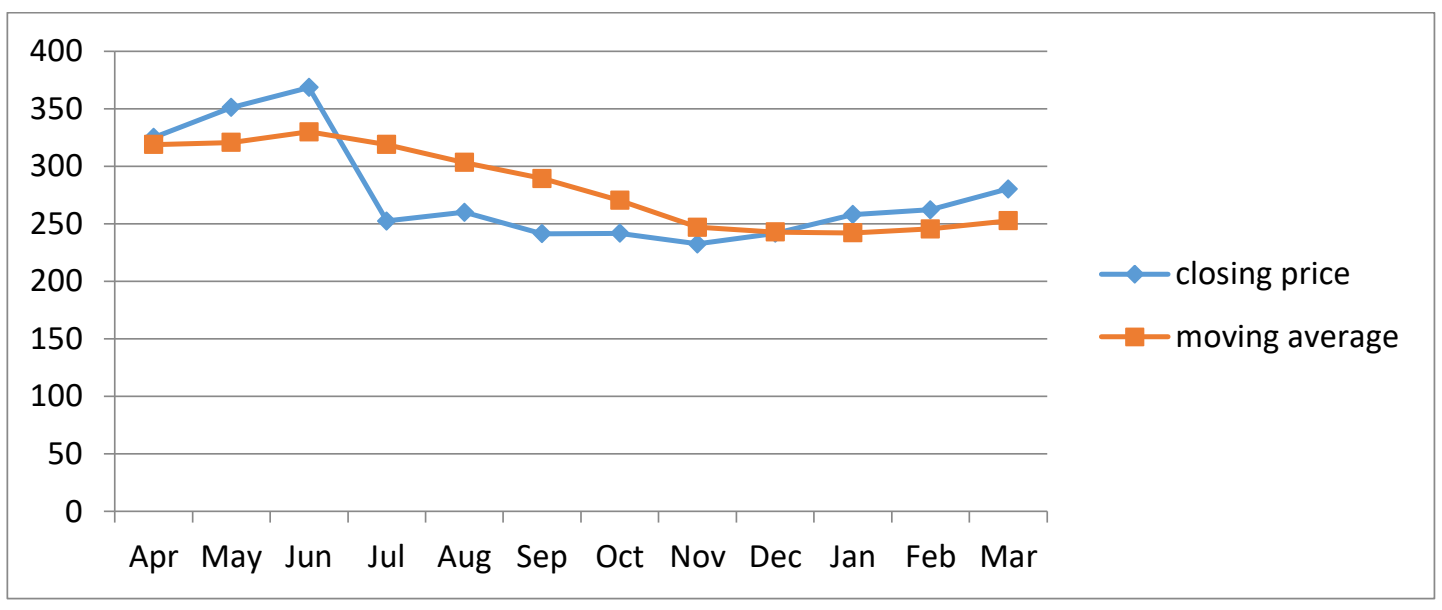

\section{Interpretation}

ITC (Indian Tobacco Company), started the year with a stock price of 324.95 and touching its peak in successive months at Rs. 368.4 in the month of June and the price on the last day was 280.03. It was at its trough point in the Nov 2016. At the initial stage it continued to trade it was trading between $300-350$ points. Then it continued to trade between 230-250 but suddenly rose to 260 on $2^{\text {nd }}$ August and then fell down to 250. It continued to be around there till September where it again reached 260 mark and then again started to fall, going below 240 this time. In the month of November, it again started to fell, touching 232 points. At the starting of January it again rose to 240 and continued to rise up to 270-280 mark, ending on 280 at the end of the period. The moving average line is intersecting the price trend in the month of Dec, indicating a sell signal

\section{- PGHH (Apr 16 - Mar-17)}

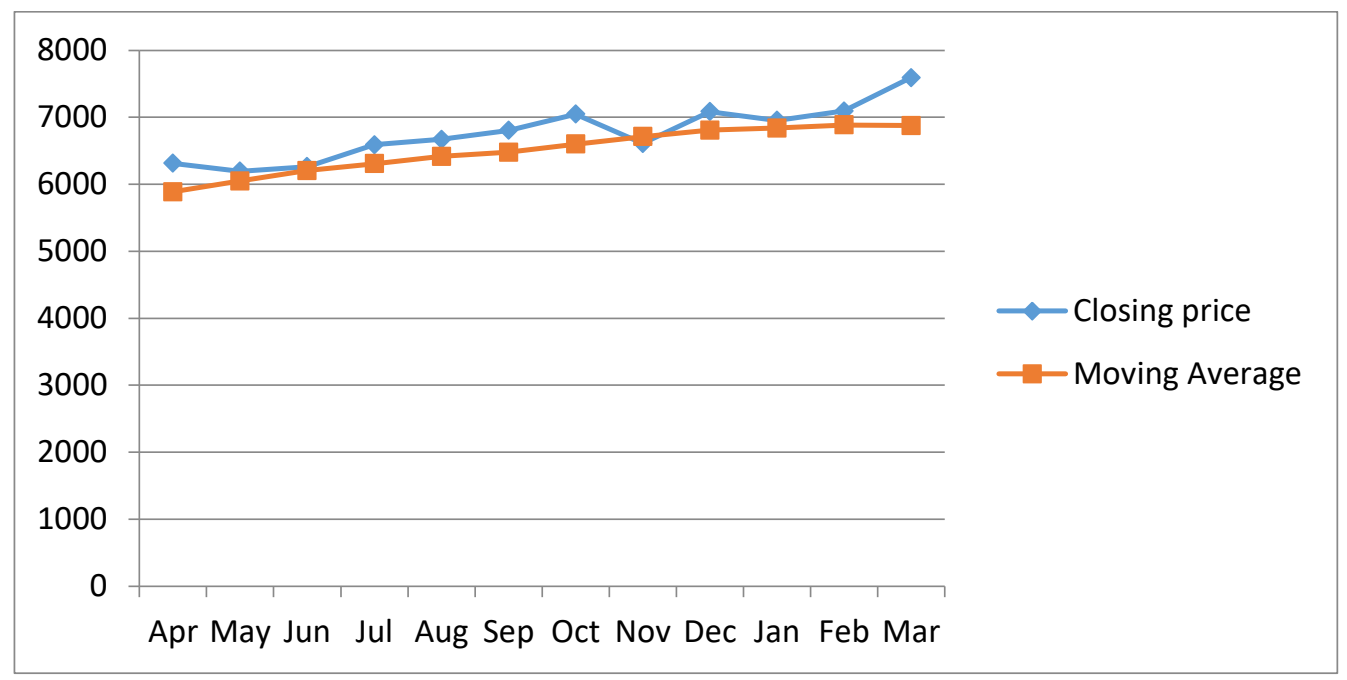




\section{Interpretation}

In the above chart I have plotted close price of PGHH (Procter and Gambler Healthcare \& Hygiene) stock trading in NSE for last one year. The year began with a price of Rs. 6314.4 and without undergoing many fluctuations in the price level, the stock price reached at its peak 7592.5 at the end of the year. Though there was a gain of $300-500$ points, as compared to the initial stage. In between July to Oct, again there was a fall in price level with a margin of approx. 700 points, may be due to the growing craze for another FMCG giant Patanjali among the public. Further the price level moved upwards touching its ultimate high of 7592.15 at the end of the year.The 100days moving average line was moving closer to the blue line

\section{Automobiles Sector}

\section{- Tata Motors (Apr 16 - Mar 17)}

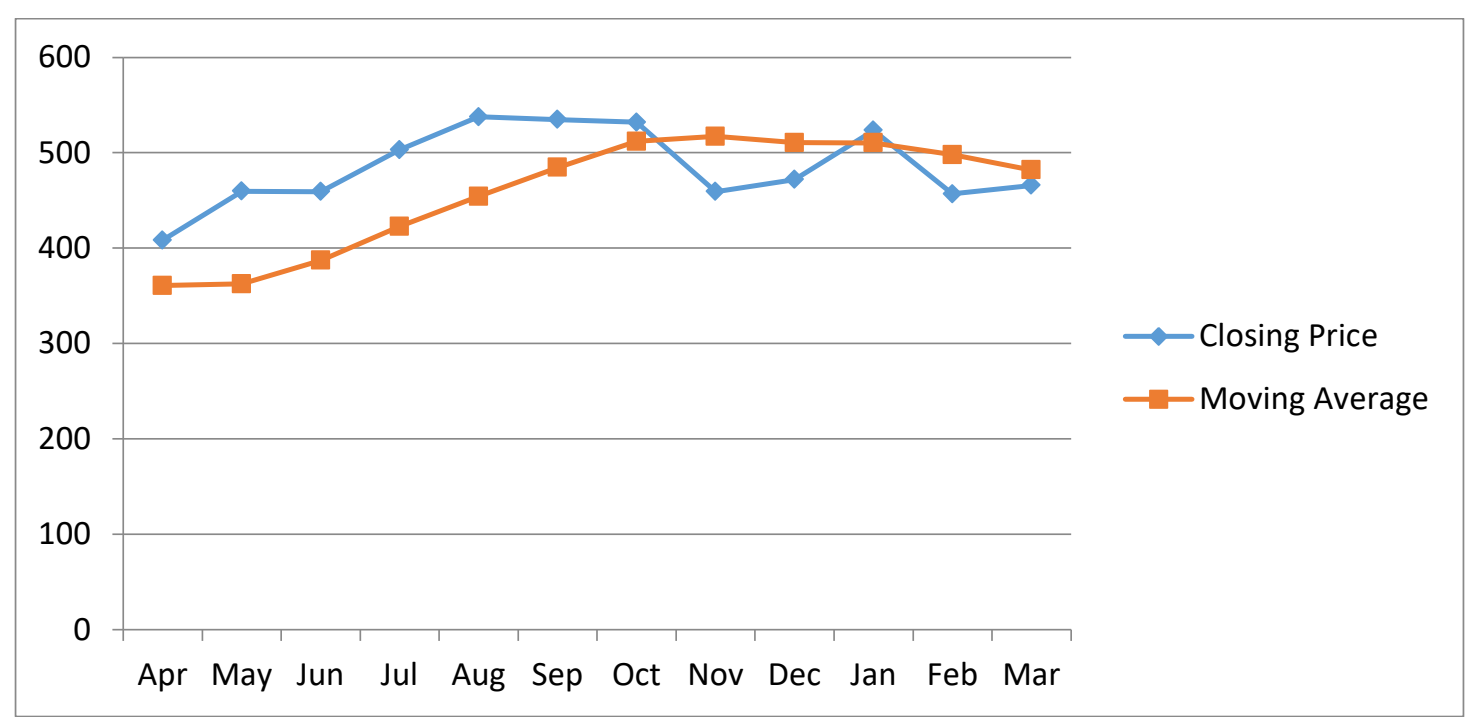

\section{Interpretation}

The year started with a price of Rs. 408.5 and underwent many fluctuations in the price level, the stock price reached at its peak of 531.5 in the month of Oct. Though there was a gain of 70-100 points, as compared to the initial stage, in between Oct to Jan, again there was a fall in price level with a margin of approx. 100 points. As per the article published by NdtvProfit, the primary reason behind the fall in the stock prices in Fiscal 2016 was declining prices of crude oil, with effect to the diminishing demand of oil. Further the price level moved upwards touching its ultimate high of 510.4.The 100days moving average line was moving below the blue line and the downward penetration reflects a sell signal. 


\section{- Maruti (Apr 16 - Mar 17)}

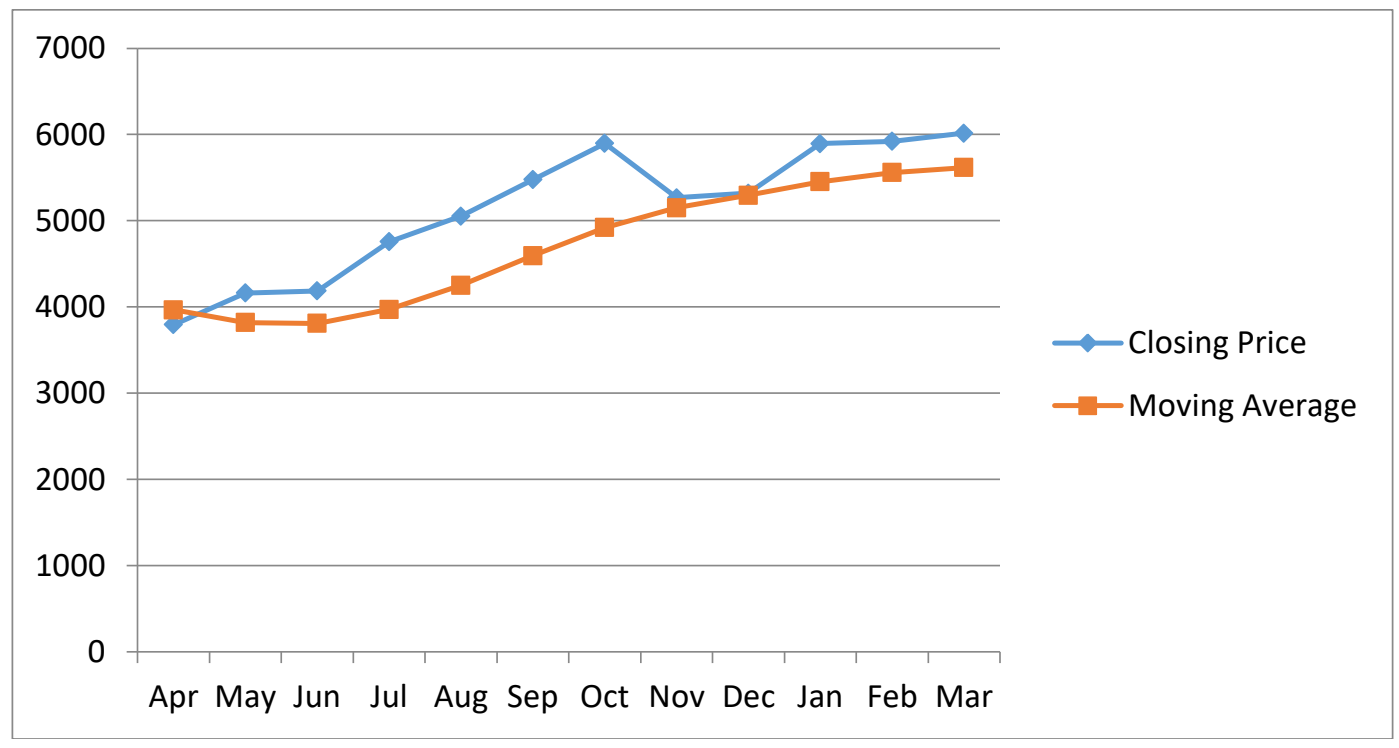

\section{Interpretation}

In the above chart, I plotted close price of Maruti Suzuki stock trading in NSE for last one year. The Maruti stock price reached at a peak of 5896.15 points in the month of Oct and touched a trough point of 4162 at the initial months of the year. The SMA line was below the closing price line till the month of Nov, then moved slightly upward in the last three months of the year 2016 and touches the price line in the month of Dec. At the end of the year, there was a narrow gap between the price and SMA line, which shows a bull trend in near future.

\section{Conclusion}

The analysis done in the paper provides us the proof of Bull Market and Bear Market prevailing in Indian Stock Market. From the line chart analysis of trend we got ample idea about how the market behaves in different long period spans. The reasons where found out to be both micro as well as macro-economic factors. From changes in company's financial performance to changes in industry affect the market and investor sentiments. The political as well as global factors may bring on bull or bear phase in the market.

The investor perception over any company or industry may change in a small time span too. The moving average analysis gave us how the investor could use buy and sell signals to entry or exist the market at right time to take advantages of either bull or bear phase.

Bull and Bear phase do not specifically stick to a specific stock. As bull and bear phase are created by investor themselves on how they perceive the stock or industry at a particular time. As the investor perception changes the phase for the stock or industry too changes. Investor perceptions are guided by both fundamental factors as well as sentiments of the market. 


\section{References}

[1] Barber, Brad M., Terrance Odean (2000)."Trading is hazardous to your wealth: The common stock investment performance of individual investors". Journal of Finance, 55, p 773- 806.

[2] Bodie\& Kane (2004), Securities Analysis \& Portfolio Management. 6th edition

[3] Edwards, Magee (1997) "Technical Analysis of Stock Trends". Fifth edition, Boston.

[4] Eugene F.Fama (1965). "The Study of Stock Prices". Journal of Business,

[5] Fernando Fernández-Rodríguez, Simó NSosvilla-Rivero, Julián Andrada-Félix (1999). "Technical Analysis in the Madrid Stock Exchange", FEDEA -D.T.99-05, p 1-29

[6] French, K.R (1989): 'Stock returns and the week-end effect', Journal of Financial Economics, 1989 8(1): 56-59.

[7] GuoLiang,ZhouWeixing (2010).An Empirical Analysis of the Volume Price Relation Using High-Frequency Data in the Chinese StockMarket[J].Chinese Journal of Management, ,7(8):1242-1247.

[8] Gupta, L.G (2003). "Stock Market Investorse Biggest Worries Today." Portfolio Organiser. Vol.41, No.5, 2003, p 47-51

[9] Li Fujun,DaQingli (2005). Volatility between volume and price returns:evidence from Chinese stock markets [J].Journal of SoutheastUniversity (Natural Science Edition),35(2):308-310.

[10] Lo, Andrew, Harry Mamaysky, Jiang Wang (2000). "Foundations of Technical Analysis," Journal of Finance 54, p 1705-65.

[11] Mukherjee P. (2011). An Exploration on Volatility Across India and Some Developed and Emerging Equity Markets. Asia PacificDevelopment Journal, 18(2): 79

[12] Osler, C.L. (2000).”Support for Resistance: Technical Analysis and Intraday Exchange Rates," Federal Reserve Bank of New York Economic Policy Review 6, p 53-65.

[13] P Jain, GH Joh.(1988) The Dependence between Hourly prices and Trading Volume [J] Journal of Finance \& Quantitative Analysis, , 23:269-283.

[14] Prasanna Chandra (2008), Investment Analysis \& Portfolio Management. 3rd edition

[15] Pring Martin J. (1991): Technical Analysis, Explained 'The Successful Investors' Guide to Spotting Investment Trends and Turning Points, McGraw Hill, 1991

[16] Ravindra K., Y. Wang, (2006). "The causality between stock index returns and volumes in the asian equity markets". Journal of International Business. Res., 5, p 63-74.

[17] Sharma G. D, Singh S, \&LittG. S. (2012). Inter-Linkages between Stock Exchanges: A Study of BRIC Nations. International Journal of Marketing, Financial Services \& Management Research, 1(3): 1-17.

[18] Singh, G., \& Singh, P. (2010). Chinese and Indian Stock Market Linkages with Developed StockMarkets. Asian Journal of Finance \& Accounting,2(2): E2.

[19] Stickel, S. (1990): 'Predicting Individual Analysts Forecasts', Journal of accounting Research, 28, 1990, pp.409-417.

[20] Sundaram, S.M. (1994): „Soaring Stock Prices’, Economic and Political weekly, 26,1991,p.1184

[21] T.P. Madhusoodanan (1997), "Risk and Return: A New Look at the Indian StockMarket", Finance India, Vol. xi, No. 2, June 1997, p.p. 285-304.

[22] TripathiV. \&Sethi S. (2012). Inter Linkages of Indian Stock Market With Advanced EmergingMarkets. The Asian Economic Review, 54(3): 507-528

[23] YarramSubha Reddy (1996), "Volatility of Securities Traded on the National Stock Exchange and Bombay Stock Exchange: A Comparison”, Decision, Vol. 23, No. 1-4,Jan-Dec 1996, p.p. 124.

\footnotetext{
*Corresponding author.
}

E-mail address: biswajit_rt@ yahoo.co.in / akashkachariya89@gmail.com/mohanty.ayesha2@gmail.com 